\title{
On The Optimal Forms Finding of Shallow Foundations Made Up of Four Foothills with Explicit Considerations of Structural Perturbations
}

\author{
Koumbe Mbock*, Etoua Remy Magloire ${ }^{\#}$ \\ Department of Mathematics and Physics \\ National Advanced School of Engineering \\ Yaounde, P.O. Box 8390, Cameroon \\ E-mails: "k.mbock@yahoo.fr, " retoua@yahoo.fr \\ ${ }^{*}$ Corresponding author \\ Ayissi Raoul Domingo \\ Department of Mathematics, Faculty of Sciences \\ University of Yaounde, P.O Box812, Cameroon \\ E-mail: raoulayissi@yahoo.fr \\ Mamba Mpele ${ }^{\phi}$, Okpwe Mbarga Richard \\ Department of Civil Engineering \\ National Advanced School of Engineering, Yaounde, P.O. Box 8390, Cameroon \\ E-mails: ${ }^{\phi}$ mamba_mpele@yahoo.fr, okrichar@gmail.com
}

(Received October 25, 2018; Accepted February 26, 2019)

\begin{abstract}
In the absence of the exact footing form of shallow foundations, we develop a procedure to determine the optimal footing form made up of four foothills from the knowledge of the inexact footing forms. The structural perturbations that are the major cause of the inexact forms are approximated in linear elastic model whose the solution is used to formulate the evolutionary structural optimization problem. To stabilize the solution, a serial of decisions is made to minimize structural perturbations in finite element modeling, initial volume and design constraints. By using the evolutionary structural optimization technique, we examine if the material of efficient and inefficient perturbations is needed or not on the points of inexact forms. Our analysis shows that the loading forces can be transferred to structural perturbations when they are efficient and used to reinforce the design material. This transfer can modify geometric elements of footing in finite element analysis and the optimal solution. The results of the numerical experiment provide the optimal footing form of shallow foundation, the sizes of associated foothills and the form of inefficient perturbations. This approach allows to redesign the structures from the inexact forms and detects the errors of dimensioning.
\end{abstract}

Keywords-Perturbations, Ill-posed problems, Linear elastic model, Eurocode 7, Topology optimization, Foundations.

\section{Introduction}

The base of many tropical trees in Cameroon is made up of foothills and their structure needs more exploration as the researcher Link (1949) laid its local interpretations at Alberta, in Canada. The dimensioning using Eurocode 7 had emerged as a powerful technique and proposed in the recent years by the guide of designers to EN 1997 (2004); Orr and Farell (2012).

In geotechnical structure the analysis of dimensioning and tolerances were developed by Hillyard and Braid (1978) and other workers as Light and Gossard (1983) had applied new methods to modify a part of geometry. The researcher Olchawa and Zawalski (2014) had found that certain values of coefficients obtained by using Eurocode 7 are higher than those prescribed in the design 
International Journal of Mathematical, Engineering and Management Sciences

Vol. 4, No. 3, 601-618, 2019

https://dx.doi.org/10.33889/IJMEMS.2019.4.3-048

of shallow foundations. In accordance with the structural tolerance, some specific errors of dimensioning were detected by Zong and Mao (2015) through analysis and mathematical modeling. The performance of linear elastic models had been tested on the shallow foundations of building, bridges and trusses (Green and Zerna, 1968; Terzaghi et al., 1996; Bowles, 1996; Das, 2010; Fellenius, 2018; Mbock et al., 2019). However, the most of under- and over-dimensioning of shallow foundations arising from ill-posed problems are costly. Beyong the ill-posed problems in elasticity, inverse boundary value problems were widely solved by Eskin and Ralston (2002); Nakamura and Uhlmann (2003). Several applications of optimization to ill-posed and inverse problems were widely studied by Engl and Groetsch (2014) for stabilization of numerical solutions. The causes of the ill-posedness can arise from explicit consideration of perturbation components (Mbock, 2009). Structural failure involve often the solution of an optimization problem including the important role that plays structural reliability analysis and reinforcement (Ikpe et al., 2017; Bhunia et al., 2017; Kumar and Ram, 2018) due to the difficulty to predict the membership of some components in various field of engineering.

In topology optimization the researcher Xie et al. (2005) had designed materials to find the forms of complex structures by using the evolutionary structural optimization (ESO) method developed by Huang and Xie (2008); Huang and Xie (2010), and Jouve (2014). This intuitive method has been applied to determine if material is needed for every point in the design domain or not. The calculus of small structural change using perturbations based redesign methods have been introduced by Stetson and Palma (1976) for the large admissible perturbation methodology (LEAP). Using the evolutionary structural optimization method, the LEAP methodology was developed by Suryatama and Bernitsas (2000); Miao and Bernitsas (2006) to optimize structures. The optimal design of shallow foundations can include information on topology, shape and size optimization. More recently the mechanism of combined rupture was studied in shallow foundations by Gajo and Smith (2018).

In this paper, the foothills of shallow foundations are designed only from the knowledge of the inexact footing forms. We assume that the causes of the inexact forms are structural perturbations whose the existence do not prevent the transfer of the loading forces. Our topology optimization approach consists in removing the materials of inefficient perturbations and using the efficient perturbations to reinforce the design material needed to obtain the optimal footing form made up of four foothills.

For this, we introduce the work in this section. We describe the ill-posed problem as inverse boundary value problem for linear elasticity in Section 2 whose the stabilized solution is used in Section 3 to formulate the evolutionary structural optimization problem. In Section 4, the numerical experiments show a serial of decisions, which provides information on the optimal footing form, the sizes of the associated foothills and the inefficient perturbations form. A short summary is presented in Section 5 to conclude this work.

\section{Our Proposed Approach in the Case of Structural Perturbations}

In the absence of the exact footing forms we develop numerical procedure to find the optimal footing form of Figure 1c made up of four foothills from the knowledge of inexact forms presented in Figure 1a and 1b. 


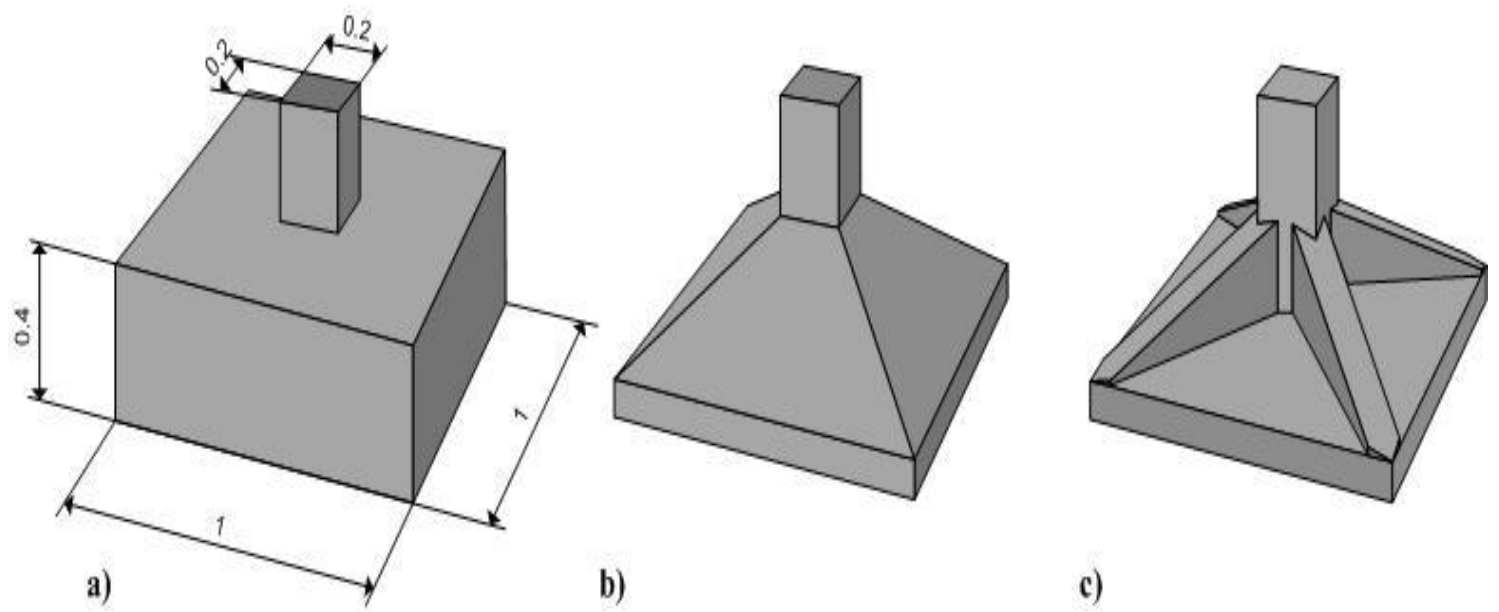

Figure 1. a) Initial footing form, b) inexact footing form and c) unknown and desired footing form.

The stability of the desired footing form requires additional constraints on structural perturbations which are considered as the major cause of the inexact footing forms. We assume that the perturbations field exists in the design domain and the forms of structural perturbations are unknown variables which do not prevent for example the compressive and shear stress to be active. The ill-posed and inverse problem consists in finding the causes of inexact forms and then we examine if they are removed for every point in the inexact domain or not. To do this, we describe the reconstruction problem through mathematical modeling in linear elasticity and solve the perturbed boundary value problem whose the stabilized solution is used to formulate the objective of the optimal footing forms. In this procedure the evolutionary structural optimization technique is based on a serial of decisions that minimizes the initial volume, structural perturbations in finite element modeling and design constraints.

\subsection{Modelling the Structural Perturbation Problem}

We consider that the shallow footing occupies a domain $\Omega$ of $\mathrm{N}$-dimensional design space $\mathbb{R}^{N}$ and the boundary of $\Omega$ is denoted by $\partial \Omega$. In general, the Hilbert space $\mathcal{L}^{2}(\Omega)$ is the set of measurable and square integrable functions in $\Omega$ and the set $\mathcal{H}^{1}(\Omega)=\left\{\omega \in \mathcal{L}^{2}(\Omega) \mid \forall \mathrm{i} \in\{1,2, \ldots, N\}, \frac{\partial \omega}{\partial \mathrm{x}_{\mathrm{i}}} \in\right.$ $\left.\mathcal{L}^{2}(\Omega)\right\}$ is the Sobolev space. 
International Journal of Mathematical, Engineering and Management Sciences

Vol. 4, No. 3, 601-618, 2019

https://dx.doi.org/10.33889/IJMEMS.2019.4.3-048

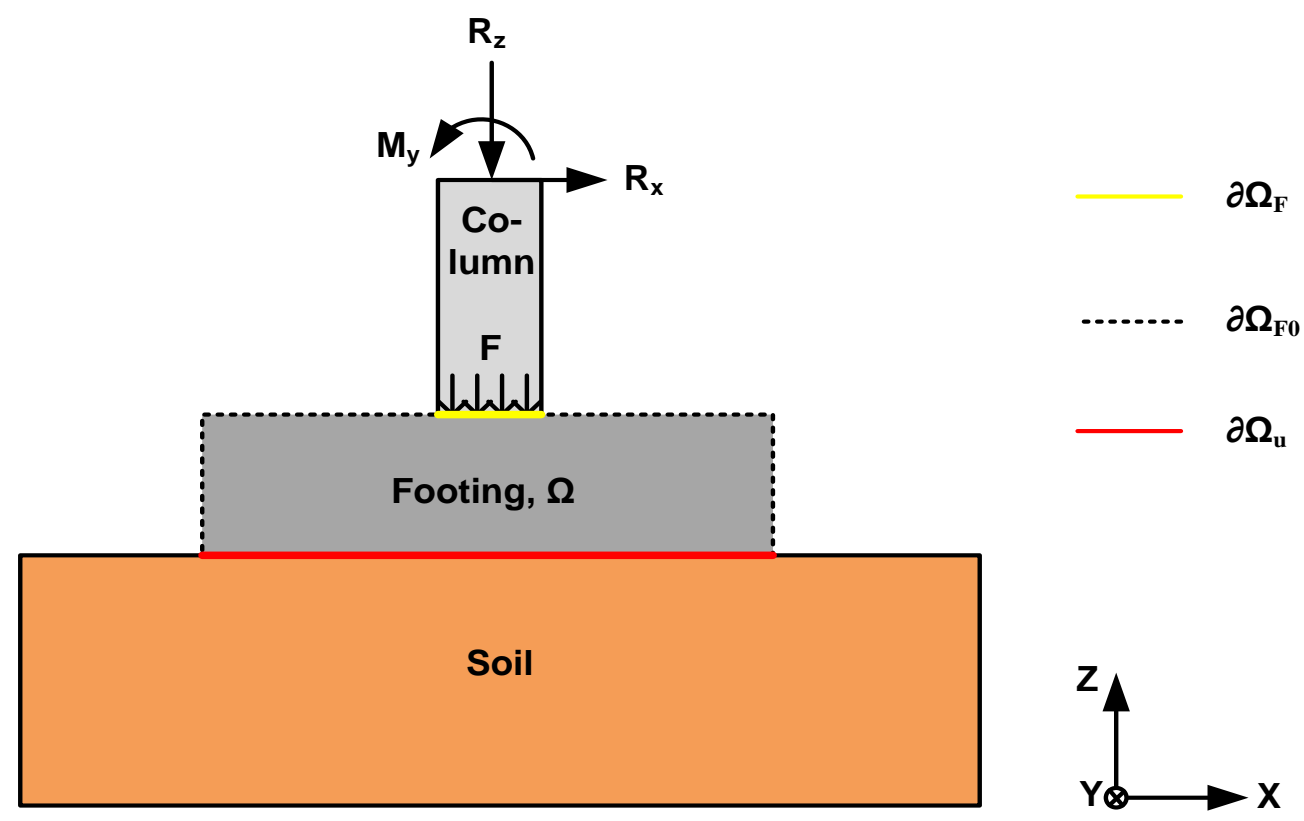

Figure 2. Shallow footing fixed at the surface of soil

At the boundary $\partial \Omega_{F}$ of the Figure 2 above, the compressive load $\mathrm{F} \in \mathcal{L}^{2}(\Omega)$ is supported by the concrete shallow footing and the moment $M \in \mathcal{L}^{2}(\Omega)$ acting on the concrete footing are normalized through the vertical forces $\mathrm{R}_{z}$. The applied forces $\mathrm{R}_{x}$ and $\mathrm{R}_{y}$ with respect to the directions $\mathrm{x}$ and $\mathrm{y}$ are neglected. In the same figure, the shallow foundation is fixed at the boundary $\partial \Omega_{u}$ where the displacement vector $\mathrm{u} \in \mathcal{H}^{1}(\Omega)$ is neglected with respect to vertical and horizontal direction. We assume that the perturbation tensor $\tilde{\sigma} \in \mathcal{L}^{2}(\Omega)^{\mathrm{N}}$ exists and can be decomposed to efficient perturbations and inefficient perturbations tensor respectively denoted by $\tilde{\sigma}_{\mathrm{e}} \in \mathcal{L}^{2}(\Omega)^{\mathrm{N}}$ and $\tilde{\sigma}_{\mathrm{i}} \in \mathcal{L}^{2}(\Omega)^{\mathrm{N}}$. Those perturbations are not observable directly where the loading forces $\mathrm{F}$ do not act. In our setting, the known stress tensor $\sigma \in \mathcal{L}^{2}(\Omega)^{\mathrm{N}}$ are employed such that the difference $\sigma-\lambda \tilde{\sigma}=\sigma_{0} \in \mathcal{L}^{2}(\Omega)^{\mathrm{N}}$ is the new stress tensor where $\lambda$ is a positive weighting factor. The overall boundary is $\partial \Omega=\partial \Omega_{\mathrm{F}} \cup \partial \Omega_{u} \cup \partial \Omega_{\mathrm{F}_{0}}$ and the boundary $\partial \Omega_{\mathrm{F}_{0}}$ is the variable part of the footing including the boundary variables of structural perturbations denoted by $\partial \Omega_{\widetilde{\sigma}_{\mathrm{e}}}$ and $\partial \Omega_{\widetilde{\sigma}_{\mathrm{i}}}$. By observing the Figure $1 \mathrm{~b}$, the constant directional force $\mathrm{F}$ induced by the load tends to compress and shear the footing from the boundary $\partial \Omega_{F}$ while the force applied on theboundary $\partial \Omega_{\mathrm{F}_{0}}=\mathrm{C}_{\partial \Omega}^{\partial \Omega_{\mathrm{F}} \cup \partial \Omega_{\mathrm{u}}}$ is equal to zero. The divergent of $\sigma_{0}$ denoted by $\operatorname{div} \sigma_{0} \in \mathcal{L}^{2}(\Omega)$ cannot measure with accuracy how much the flow is expanding at a given point $p \in \Omega$. Due to the elastic properties of the concrete footing, one considers the symmetric matrix function $\mathrm{A}(\mathrm{x})=$ $\left(a_{i, j}(x)\right)_{1 \leq i, j \leq N} \in I^{N \times N}$ and the unit vector external to $\Omega$ denoted by $n=\left(n_{\mathrm{i}}\right)$ with $1 \leq \mathrm{i} \leq \mathrm{N}$. According to the Hooke law, the unit vector to the stress tensor $A \nabla u=\sigma$ is different from the one with the new stress tensor $\sigma_{0} \in \mathcal{L}^{2}(\Omega)^{\mathrm{N}}$. One can consider the perturbed boundary value problem stated as:

$\operatorname{div} \sigma_{0}=0, \quad$ in $\Omega$ 
International Journal of Mathematical, Engineering and Management Sciences

Vol. 4, No. 3, 601-618, 2019

https://dx.doi.org/10.33889/IJMEMS.2019.4.3-048

$\mathrm{u}=0, \quad$ on $\partial \Omega_{u}$

$\mathrm{F}=\sigma_{0} \cdot \mathrm{n}=0, \quad$ on $\partial \Omega_{\mathrm{F}}$

$\mathrm{F}=\sigma_{0} \cdot \mathrm{n}=0, \quad$ on $\partial \Omega_{\mathrm{F}_{0}}$

The Hilbert space $\mathcal{H}_{\mathrm{s}}=\left\{\mathrm{u} \in \mathcal{H}^{1}(\Omega) \mid \mathrm{u}=0\right.$ on $\left.\partial \Omega_{\mathrm{u}}\right\}$ is the solution space and the displacement vector $\mathrm{u} \in \mathcal{H}_{\mathrm{s}}$ cannot be found from the ill-posed variational formulation stated as:

$\int_{\Omega} \operatorname{div} \sigma_{0}(\mathrm{x}) \cdot \mathrm{v}(\mathrm{x}) \mathrm{dx}=-\int_{\Omega} \sigma_{0}(\mathrm{x}) \cdot \nabla \mathrm{v}(\mathrm{x}) \mathrm{dx}+\int_{\partial \Omega} \sigma_{0}(\mathrm{x}) \mathrm{v}(\mathrm{x}) \cdot \mathrm{n}(\mathrm{x}) \mathrm{ds}, \forall \mathrm{v} \in \mathcal{H}_{\mathrm{s}}$

It looks like the volume and the surface force are neglected or do not exist in perturbation equations (1) and (3). The deformation cannot be modeled by the displacement vector and the boundaries $\partial \Omega_{\widetilde{\sigma}}$ and the domain $\Omega_{\widetilde{\sigma}}$ of perturbations are unknown design variables. The structural perturbations seem to be the causes of the ill-posedness, but not all the types of structural perturbations are inefficient. The perturbation model equations (1-4) can be rewritten as:

$$
\begin{aligned}
\operatorname{div} \sigma & =\lambda \operatorname{div} \tilde{\sigma}, & & \text { in } \Omega \\
\mathrm{u} & =0, & & \text { on } \partial \Omega_{\mathrm{u}} \\
\sigma . \mathrm{n} & =\lambda \tilde{\sigma} \cdot \mathrm{n}, & & \text { on } \partial \Omega_{\mathrm{F}} \\
\sigma . \mathrm{n} & =\lambda \tilde{\sigma} \cdot \mathrm{n}, & & \text { on } \partial \Omega_{\mathrm{F}_{0}}
\end{aligned}
$$

where $\lambda>0$ is the weighting factor associated to the structural perturbations. In the model equations (6-9) the structural perturbations exist on the boundary $\partial \Omega_{\mathrm{F}_{0}}$ where the loading force $\mathrm{F}$ does not act. Also they exist in the design domain $\Omega$ and on the boundary $\partial \Omega_{\mathrm{F}}$ where the loading forces $\mathrm{F}$ are applied. In the perturbed model equations (6-9), the volume and surface force can be corrupted by the variables of structural perturbations. To allow the transfer of loading forces to geometric element of structural perturbations in finite element modeling, some approximations are required for stabilization. 
International Journal of Mathematical, Engineering and Management Sciences

Vol. 4, No. 3, 601-618, 2019

https://dx.doi.org/10.33889/IJMEMS.2019.4.3-048

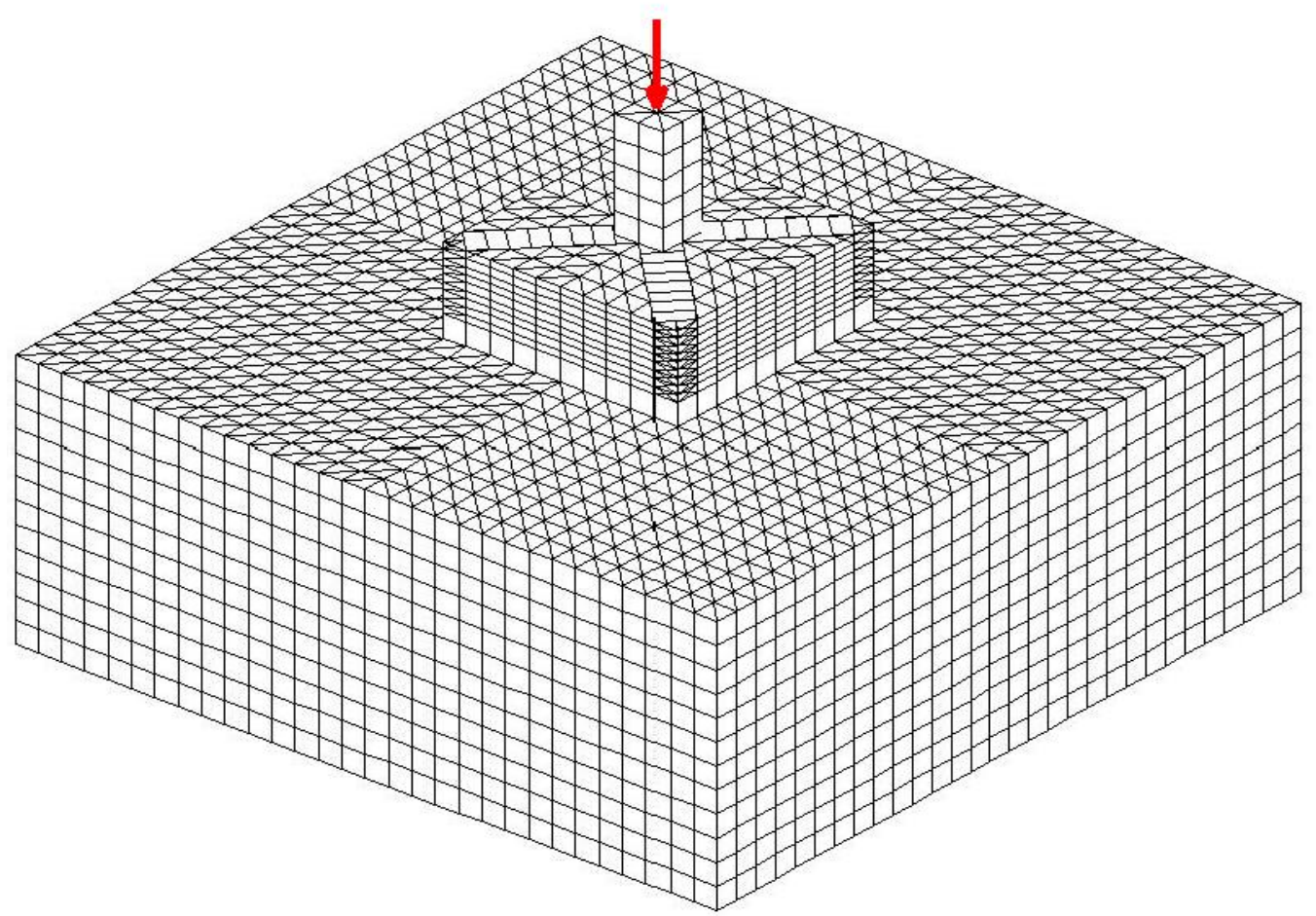

Figure 3. Finite element modeling of the initial shallow foundation fixed at the surface of the soil

\subsection{Our Inverse Boundary Value System}

Two types of perturbations tensor are considered in this analysis, namely the efficient perturbations tensor $\tilde{\sigma}_{\mathrm{e}}$ and the inefficient perturbations tensor $\tilde{\sigma}_{\mathrm{i}}$. The loading forces are transferred only to elements of efficient perturbations that reinforce the design material and modify geometric elements in finite element analysis. Thus, the volume and surface force exist and they are variables that depend on the efficient perturbations tensor $\tilde{\sigma}_{\mathrm{e}}$ when the fully stress material is needed. A part of loading forces can be supported by the structural perturbations when the total load cannot be transferred to materials of the design domain. More general we can consider the following approximations:

a) In equation (6), $\operatorname{div} \sigma \neq 0$ in $\Omega \Rightarrow \forall \tilde{\sigma} \in \mathcal{L}^{2}(\Omega)^{\mathrm{N}}, \exists \mathrm{f} \in \mathcal{L}^{2}(\Omega)$ such that $\lambda \operatorname{div} \tilde{\sigma} \approx \mathrm{f}(\tilde{\sigma})$.

b) In equation (8), $\sigma . \mathrm{n} \neq 0$ on $\partial \Omega \Rightarrow \forall \tilde{\sigma} \in \mathcal{L}^{2}(\Omega)^{\mathrm{N}}, \exists g_{0} \in \mathcal{L}^{2}\left(\partial \Omega_{\mathrm{F}}\right)$ such that $\lambda \tilde{\sigma} . \mathrm{n} \approx g_{0}(\tilde{\sigma})$

c) In equation (9), $\sigma . \mathrm{n} \neq 0$ on $\partial \Omega_{\mathrm{F}_{0}} \Rightarrow \forall \tilde{\sigma} \in \mathcal{L}^{2}(\Omega)^{\mathrm{N}}, \exists 0 \in \mathcal{L}^{2}\left(\partial \Omega_{\mathrm{F}_{0}}\right)$ such that $\lambda \tilde{\sigma} . \mathrm{n} \approx$ $0_{\mathcal{L}^{2}\left(\partial \Omega_{\mathrm{F}_{0}}\right)} \cdot$

The analysis of structural perturbations and existence proofs of $\mathrm{f}(\tilde{\sigma})$ and $g_{0}(\tilde{\sigma})$ are not from interest because our proposed approach is capable to find the causes of the inexact forms numerically. These causes are geometric elements of inefficient perturbations in the design domain of Figure 3. With the approximations mentioned above, the Dirichtlet condition (7) is 
International Journal of Mathematical, Engineering and Management Sciences

Vol. 4, No. 3, 601-618, 2019

https://dx.doi.org/10.33889/IJMEMS.2019.4.3-048

satisfied in the solution space $\mathcal{H}_{\mathrm{s}}$ while the Neumann conditions (8) and (9) are imposed until having the variational problem given by:

$\int_{\Omega} \mathrm{A} \nabla \mathrm{u} \cdot \nabla \mathrm{vdx}=\int_{\Omega} \mathrm{f}(\tilde{\sigma}) \cdot \mathrm{vdx}+\int_{\partial \Omega_{\mathrm{F}}} g_{0}(\tilde{\sigma}) \cdot \mathrm{vds}, \forall \mathrm{v} \in \mathcal{H}_{\mathrm{s}}$

where the bilinear form $\int_{\Omega} A \nabla u . \nabla v d x=b(u, v) \in \mathcal{H}_{s}(\Omega)$ can admit a quadratic form denoted by $q(v)$. According to the theory of Lax-Milgram, the unique solution of the variational problem (10) is also the unique solution of the inverse boundary value problem given by:

$$
\begin{aligned}
\operatorname{div} \sigma & =\mathrm{f}(\tilde{\sigma}), & & \text { in } \Omega \\
\mathrm{u} & =0, & & \text { on } \partial \Omega_{\mathrm{u}} \\
\sigma . \mathrm{n} & =g_{0}(\tilde{\sigma}), & & \text { on } \partial \Omega_{\mathrm{F}} \\
\sigma . \mathrm{n} & =0, & & \text { on } \partial \Omega_{\mathrm{F}_{0}}
\end{aligned}
$$

Its stability depends continuously on the surface force $g_{0}(\widetilde{\sigma}) \in \mathcal{L}^{2}\left(\partial \Omega_{\mathrm{F}}\right)$, the volume force $\mathrm{f}(\widetilde{\sigma}) \in$ $\mathcal{L}^{2}(\Omega)$ and the geometry of elements of structural perturbations. In the Hilbert space $\mathcal{H}_{\mathrm{s}}$ the energy functional is expressed as:

$\mathrm{J}(\mathrm{v}, \widetilde{\sigma})=\frac{1}{2} \mathrm{q}(\mathrm{v})-\left(\int_{\Omega} \mathrm{f}(\widetilde{\sigma}) \cdot \mathrm{vdx}+\int_{\partial \Omega_{\mathrm{F}}} g_{0}(\widetilde{\sigma}) \cdot \mathrm{vds}\right)$

The displacement vector is obtained by minimizing $\mathrm{J}(\mathrm{v})$ and we have:

$$
\mathrm{u}=\arg \min _{\mathrm{v} \in \mathcal{H}_{\mathrm{s}}(\Omega)} \mathrm{J}(\mathrm{v}, \widetilde{\sigma})
$$

We are interested not only on geometric elements of structural perturbations which contribute to model the deformations, but also in how the displacement vector changes when the type of structural perturbations changes. If $\tilde{\sigma}=\tilde{\sigma}_{\mathrm{e}}$ and $\tilde{\sigma}_{\mathrm{i}} \neq 0$ then the structural perturbations contribute not only to model the deformations, but also to reinforce fully stresses material of the design domain $\Omega$. It does not mean that the material of inefficient perturbations does not exist or the form of the design domain is exact otherwise $\tilde{\sigma}_{\mathrm{i}}=0$. This case participates faster to the objective of optimal forms finding than the case where the volume force depends only on the inefficient perturbations if $\tilde{\sigma}=\tilde{\sigma}_{\mathrm{i}}$. In this particular case the structural perturbations can reinforce under stresses material of the design domain $\Omega$ and can participate to the mechanism of rupture in shallow foundations.

\section{Proposition 2.1:}

Let $\mathrm{J}(\mathrm{v}, \widetilde{\sigma})$ be the energy functional defined for $\mathrm{v} \in \mathcal{H}_{\mathrm{s}}(\Omega)$ and $\tilde{\sigma}=\tilde{\sigma}_{\mathrm{e}} \in \mathcal{L}^{2}(\Omega)^{\mathrm{N}}$.

Let $\mathrm{u} \in \mathcal{H}_{\mathrm{s}}(\Omega)$ be the unique solution of the variational problem (10).

(i) If $u$ is the unique solution of inverse boundary value problem (11-14) obtained by solving the energy minimization problem (16), then $\mathrm{u}$ is also the unique solution of the perturbed boundary values problem (1-4). 
International Journal of Mathematical, Engineering and Management Sciences

Vol. 4, No. 3, 601-618, 2019

https://dx.doi.org/10.33889/IJMEMS.2019.4.3-048

(ii) If $\mathrm{f}(\widetilde{\sigma}) \approx \mathrm{f}$ and $\mathrm{g}_{0}(\widetilde{\sigma}) \approx \mathrm{g}_{0}$, then the unique solution of the perturbed boundary values problem(1-4) is also the unique solution of the linear elastic model:

$$
\begin{aligned}
\operatorname{div} \sigma & =-\mathrm{f}, & & \text { on } \Omega \\
\mathrm{u} & =0, & & \text { in } \partial \Omega_{\mathrm{u}} \\
\sigma . \mathrm{n} & =\mathrm{g}_{0}, & & \text { in } \partial \Omega_{\mathrm{F}} \\
\sigma . \mathrm{n} & =0, & & \text { in } \partial \Omega_{\mathrm{F}_{0}}
\end{aligned}
$$

This proposition has been sequentially demonstrated in the analysis mentioned above and the solution is not more unique when the efficient perturbations are inside and apart from the design domain $\Omega$.

\section{Topology Optimization with Structural Perturbations}

\subsection{Design Constraints and Objective Functions}

Since $\Omega_{\mathrm{F}_{0}} \subset \Omega$ is the part of the initial footing volume $\mathrm{V}_{0} \in \mathcal{L}^{2}(\Omega)$ that varies when the loading forces act on the boundary $\partial \Omega_{\mathrm{F}}$. The form of the domain changes with respect to the directions $\mathrm{x}, \mathrm{y}$ and $\mathrm{z}$ and also the forms of the structural perturbations $\Omega_{\widetilde{\sigma}}$. Thus, the unknown forms $\Omega_{\mathrm{x}}, \Omega_{\mathrm{y}} \Omega_{\mathrm{z}}$ and $\Omega_{\widetilde{\sigma}}$ are the variables of the shallow footing design. Let $\Omega_{\mathrm{ad}}$ be the set of admissible forms such that:

$\Omega_{\mathrm{ad}}=\left\{\Omega_{\mathrm{x}} \cup \Omega_{\mathrm{y}} \cup \Omega_{\mathrm{z}} \cup \Omega_{\widetilde{\sigma}}=\Omega \mid \partial \Omega_{\mathrm{F}} \cup \partial \Omega_{\mathrm{u}} \subset \partial \Omega\right.$ and $\left.\int_{\Omega} \mathrm{dp}=\mathrm{V}_{0},(\mathrm{x}, \mathrm{y}, \mathrm{z}) \in \mathrm{R}^{3}\right\}$

Let $\Omega_{\mathrm{h}}$ and $\Omega_{\mathrm{g}}$ be respectively the set of the objective functions and admissible structural constraints such that:

$$
\begin{aligned}
& \Omega_{\mathrm{h}}=\left\{(\sigma, \widetilde{\sigma}, \mathrm{u}) \in\left(\mathcal{L}^{2}(\Omega)^{\mathrm{N}}\right)^{2} \times \mathcal{H}_{\mathrm{s}} \mid \mathrm{h}_{\mathrm{j}}\left(\Omega, \mathrm{f}(\widetilde{\sigma}), g_{0}(\widetilde{\sigma}), \mathrm{u}, \alpha\right)=\mathrm{V}_{\mathrm{j}}, \mathrm{j}=1,2, \ldots, \mathrm{m}\right\} \\
& \Omega_{\mathrm{g}}=\left\{(\sigma, \widetilde{\sigma}, \mathrm{u}) \in\left(\mathcal{L}^{2}(\Omega)^{\mathrm{N}}\right)^{2} \times \mathcal{H}_{\mathrm{s}} \mid \mathrm{g}_{\mathrm{i}}\left(\Omega, \mathrm{f}(\widetilde{\sigma}), g_{0}(\widetilde{\sigma}), \mathrm{u}, \alpha\right) \leq 0, \mathrm{i}=1,2, \ldots, \mathrm{n}\right\}
\end{aligned}
$$

where $\alpha$ is a real fixed parameter of ESO, $\mathrm{n}$ is the number of structural constraints and $m$ is the number of objective functions. The initial volume $\mathrm{V}_{0}=\mathrm{h}_{1}\left(\Omega, \mathrm{f}(\widetilde{\sigma}), g_{0}(\widetilde{\sigma}), \mathrm{u}, \alpha\right)$ is considered as a continuous function of several variables and dimensioned through the Eurocode 7 . Intuitively one applies the ESO method to find the unknown footing form given in Figure 1c from the knowledge of inexact forms given in $1 \mathrm{a}$ and $1 \mathrm{~b}$. We eliminate the materials of inefficient perturbations where the compressive stress $\sigma_{\mathrm{zz}}$, the shear stresses $\sigma_{\mathrm{xz}}$ and $\sigma_{\mathrm{yz}}$ are not active. It means that the optimal form can satisfy the following constraints:

$$
\begin{aligned}
& \mathrm{g}_{1}\left(\Omega, \mathrm{f}(\widetilde{\sigma}), g_{0}(\widetilde{\sigma}), \mathrm{u}, \alpha\right)=\frac{\sigma_{\mathrm{zz}}}{\sigma_{\mathrm{zz}}^{\max }}-0.01 \leq 0 \\
& \mathrm{~g}_{2}\left(\Omega, \mathrm{f}(\widetilde{\sigma}), g_{0}(\widetilde{\sigma}), \mathrm{u}, \alpha\right)=\frac{\sigma_{\mathrm{zz}}}{\sigma_{\mathrm{xz}}^{\max }}-0.02 \leq 0 \\
& \mathrm{~g}_{3}\left(\Omega, \mathrm{f}(\widetilde{\sigma}), g_{0}(\widetilde{\sigma}), \mathrm{u}, \alpha\right)=\frac{\sigma_{\mathrm{zz}}}{\sigma_{\mathrm{yz}}^{\max }}-0.02 \leq 0
\end{aligned}
$$


International Journal of Mathematical, Engineering and Management Sciences

Vol. 4, No. 3, 601-618, 2019

https://dx.doi.org/10.33889/IJMEMS.2019.4.3-048

$$
\begin{aligned}
& \mathrm{g}_{4}\left(\Omega, \mathrm{f}(\widetilde{\sigma}), g_{0}(\widetilde{\sigma}), \mathrm{u}, \alpha\right)=\sigma_{\mathrm{zz}}^{\max }-\sigma_{\mathrm{adz}} \leq 0 \\
& \mathrm{~g}_{5}\left(\Omega, \mathrm{f}(\widetilde{\sigma}), g_{0}(\widetilde{\sigma}), \mathrm{u}, \alpha\right)=\sigma_{\mathrm{xz}}^{\max }-\sigma_{\mathrm{adx}} \leq 0 \\
& \mathrm{~g}_{6}\left(\Omega, \mathrm{f}(\widetilde{\sigma}), g_{0}(\widetilde{\sigma}), \mathrm{u}, \alpha\right)=\sigma_{\mathrm{yz}}^{\max }-\sigma_{\mathrm{ady}} \leq 0
\end{aligned}
$$

where the maximum available values of structural stresses are respectively denoted by $\sigma_{\mathrm{xz}}^{\max }, \sigma_{\mathrm{yz}}^{\max }$ and $\sigma_{\mathrm{zz}}^{\max }$. At a footing point $\mathrm{p} \in \Omega$ those values muss be lower than its corresponding maximal permissible values denoted respectively by $\sigma_{\mathrm{adz}}, \sigma_{\mathrm{adx}}$ and $\sigma_{\mathrm{ady}}$. Other constraints arise from the resolution of the perturbed model equations (1-4) whose the unique solution satisfies two inequality constraints such as:

$$
\begin{aligned}
& \sigma-\sigma_{\mathrm{ad}}=\mathrm{g}_{7}\left(\Omega, \mathrm{f}(\widetilde{\sigma}), g_{0}(\widetilde{\sigma}), \mathrm{u}, \alpha\right) \leq 0 \\
& \mathrm{u}-\mathrm{u}_{\mathrm{ad}}=\mathrm{g}_{8}\left(\Omega, \mathrm{f}(\widetilde{\sigma}), g_{0}(\widetilde{\sigma}), \mathrm{u}, \alpha\right) \leq 0
\end{aligned}
$$

where $\sigma_{\mathrm{ad}} \in \Omega_{\mathrm{g}}$ and $\mathrm{u}_{\mathrm{ad}} \in \Omega_{\mathrm{g}}$ are respectively values of permissible stresses and displacements.

\subsection{Statement of the Constrained Minimization Problem}

Our topology optimization decides if materials of inefficient or efficient perturbations are needed or not for every point of inexact domain to determine optimal footing forms made up of foothills.

Since we have the objective function at the first stage $\mathrm{j}=1$, the design constraints (24-29) and those obtained by modeling the deformation of the structure (30-31). The constrained minimization problem is stated as:

$\min _{\Omega_{\mathrm{x}}, \Omega_{\mathrm{y}}, \Omega_{\mathrm{x}}, \Omega_{\widetilde{\sigma}} \in \Omega_{\mathrm{ad}}} \mathrm{h}_{\mathrm{j}}\left(\Omega, \mathrm{f}(\widetilde{\sigma}), g_{0}(\widetilde{\sigma}), \mathrm{u}, \alpha\right)$

subject to $\left\{\mathrm{g}_{\mathrm{i}}^{\mathrm{j}}\left(\Omega, \mathrm{f}(\widetilde{\sigma}), g_{0}(\widetilde{\sigma}), \mathrm{u}, \alpha\right) \leq 0\right.$, for $1 \leq \mathrm{i} \leq \mathrm{n}, 1 \leq \mathrm{j} \leq \mathrm{m}$

where $n=8$ is the number of structural constraints and $m$, the number of decision stages at each iteration $\mathrm{k}$ whose the value is fixed from the convergence criterion. The constrained minimization problem (32-33) consists in determining the optimal geometric forms with respect to $\mathrm{x}, \mathrm{y}$ and $\mathrm{z}$ directions and the form of structural perturbations $\Omega_{\widetilde{\sigma}}$ which minimize the volume $h_{j}$ of the shallow footingat a finite number of decision stages. At each decision stage $\mathrm{j}$, the decisions are taken to minimize the initial volume in finite elements modeling, structural perturbations and design constraints. In Figure 4 below, the evolutionary structural optimization (ESO) technique is based on serial decisions of dimensioning at each decision stage. 
International Journal of Mathematical, Engineering and Management Sciences

Vol. 4, No. 3, 601-618, 2019

https://dx.doi.org/10.33889/IJMEMS.2019.4.3-048

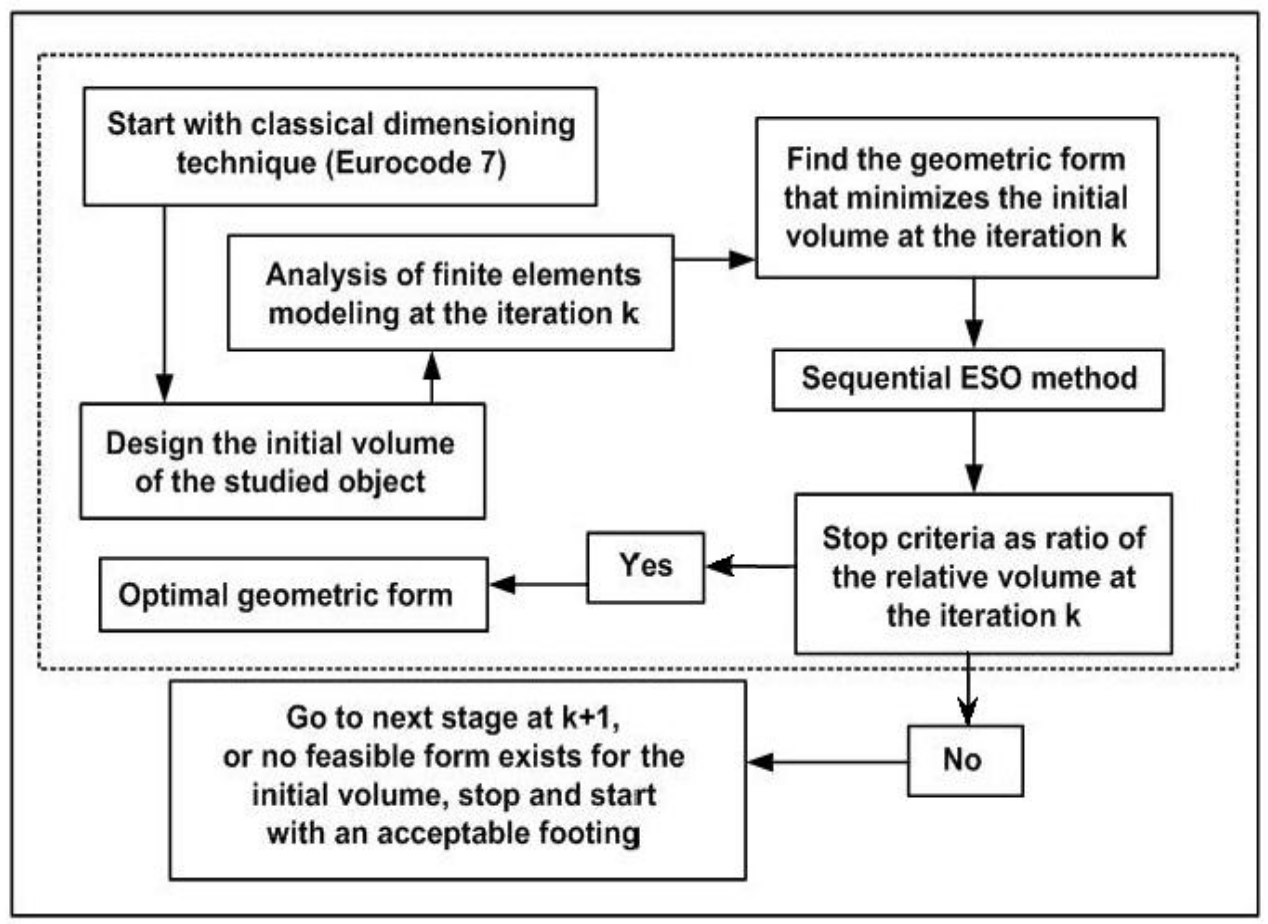

Figure 4. Flowchart of optimal forms finding

To design the foothills one removes the material of inefficient perturbations for every point of the inexact domain $\Omega$ where the loading forces are not transferred.The same initial conditions of modeling are applied on the new boundaries of the reduced volume until getting the transfer of the total load to materials of efficient perturbations. Two consecutive elimination rates $R_{k}$ and $\mathrm{RR}_{\mathrm{k}+1}$ are related by the evolutionary rate ER of stresses given by:

$\mathrm{ER}=\mathrm{RR}_{\mathrm{k}}-\mathrm{RR}_{\mathrm{k}+1}$

The elimination rate of the compressive and shear stress are initialized respectively by $1 \%$ and $2 \%$. These values can change dependently on the complexity of the footing structure. The stop criteria are fixed at the terminal iteration when the ratio of the relative volume does not exceed $1 \%$. We have the convergence criterion:

$$
\left|\frac{\mathrm{V}_{\mathrm{k}+1}-\mathrm{V}_{\mathrm{k}}}{\mathrm{v}_{\mathrm{k}}}\right| \leq 1 \%
$$

\section{Numerical Experiments}

In this section, we define the experimental data and solve the constrained minimization problem (32-33) with the guidance of the computer program CAST3M (Verpeaux et al., 1988) based on finite element analysis (Larson and Bengzon, 2013).

\subsection{Characteristics of soil:}

- Cohesion, $10 \mathrm{kPa}$

- Friction angle, $35^{\circ}$ 
International Journal of Mathematical, Engineering and Management Sciences

Vol. 4, No. 3, 601-618, 2019

https://dx.doi.org/10.33889/IJMEMS.2019.4.3-048

- Unit weight, $19 \mathrm{KN} / \mathrm{m}^{3}$

- Specific density, 2.65

- Young Modulus, $3100 \mathrm{MPa}$

- Poisson coefficient, 0.3.

4.2 Characteristics of concrete foundation:

- Characteristic resistance of concrete to28 days, $25 \mathrm{MPa}$

- Unit weight, $2300 \mathrm{~kg} / \mathrm{m} 3$

- Young Modulus,3100 MPa

- Poisson coefficient, 0.3.

4.3 List of applied loads on the shallow footing in Table 1.

Table 1. Coordinate systems with respect to $\mathrm{x}, \mathrm{y}$ and $\mathrm{z}$-axis

\begin{tabular}{|c|c|c|c|}
\hline Applied Loads & $\begin{array}{c}\text { Vertical, } \mathbf{R}_{\mathbf{z}} \\
(\mathbf{K N})\end{array}$ & Horizontal, $\mathbf{R}_{\mathbf{y}}(\mathbf{K N})$ & $\begin{array}{c}\text { Moment, } \mathbf{M}_{\mathbf{y}} \\
(\mathbf{K N}, \mathbf{m})\end{array}$ \\
\hline Permanent loads & 160 & 0 & 0 \\
\hline Exploitation loads & 60 & 0 & 0 \\
\hline Accidental loads & -10 & 0 & 0 \\
\hline
\end{tabular}

4.4 Dimensioning of the initial volume using Eurocode 7 in Table 2.

Table 2. Dimensions of the shallow footing

\begin{tabular}{|c|c|c|c|}
\hline Dimensions & Width $(\mathbf{m})$ & Lengh $(\mathbf{m})$ & Thickness $(\mathbf{m})$ \\
\hline Concrete column & 0.2 & 0.2 & - \\
\hline Concrete footing & 1 & 1 & 0.4 \\
\hline
\end{tabular}

4.5 Illustration of optimal form finding made up of four foothills at a finite number of iterations in Figure 5. 
International Journal of Mathematical, Engineering and Management Sciences

Vol. 4, No. 3, 601-618, 2019

https://dx.doi.org/10.33889/IJMEMS.2019.4.3-048

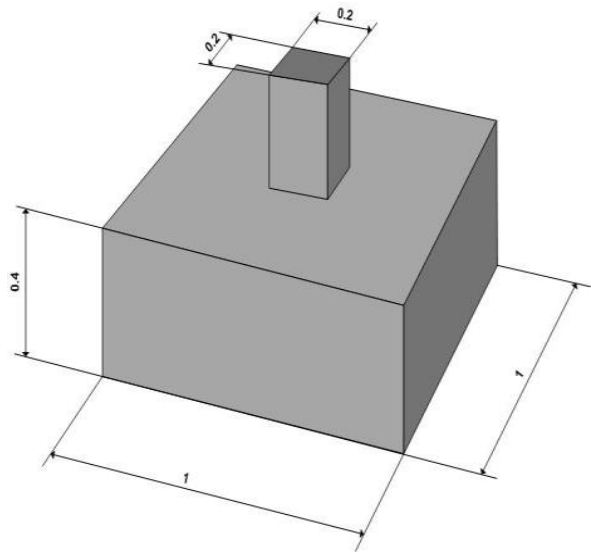

(a)

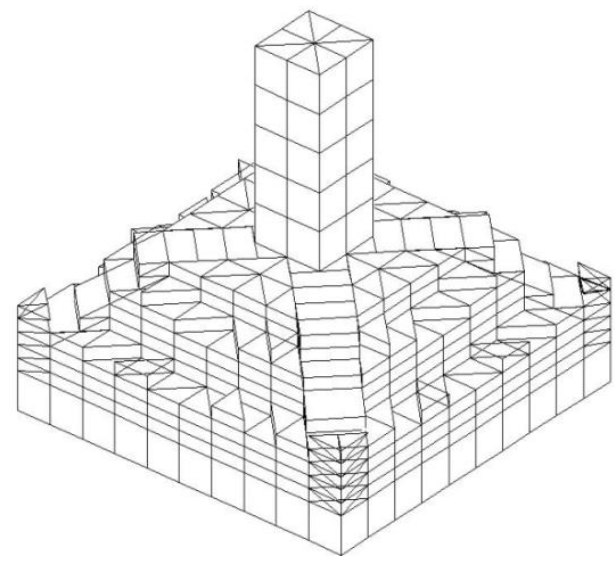

(c)

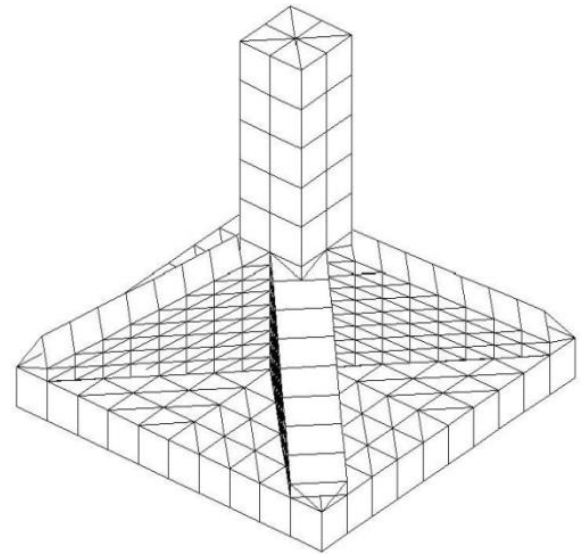

(e)

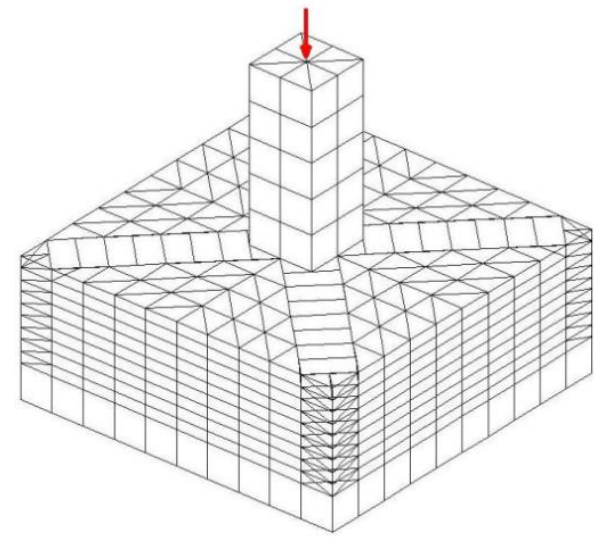

(b)

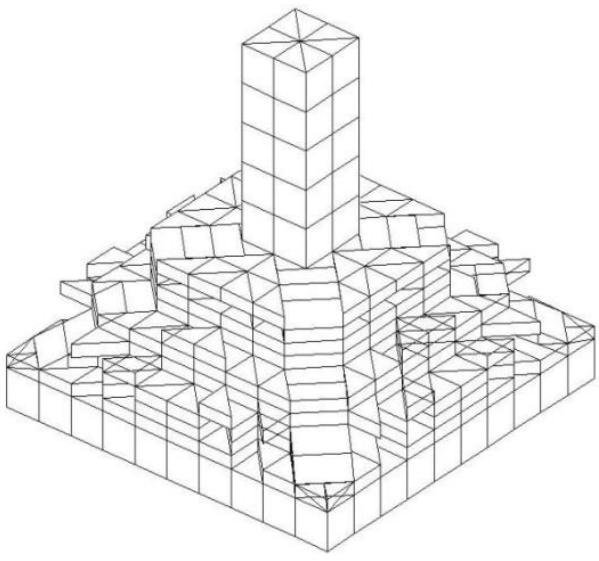

(d)

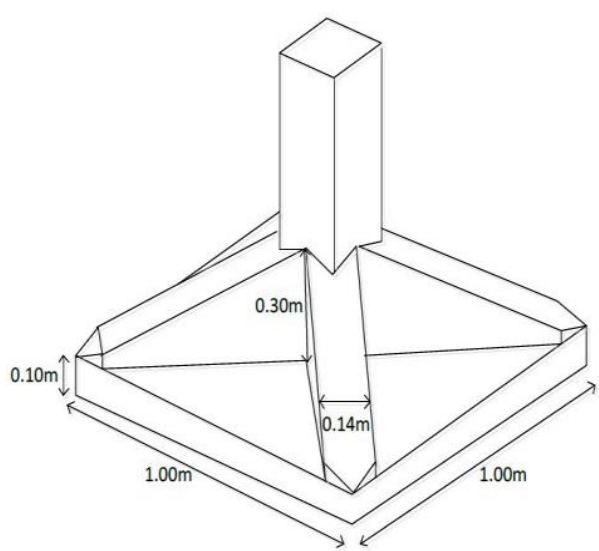

(f)

Figure 5. Initial volume for (a), finite element modeling at $k=0$ for (b), volume reduction at $k=1$ for (c) and at $k=2$ for (d), final form made up of four foothills at $k=3$ for (e) and dimensions of the final form for (f) 
International Journal of Mathematical, Engineering and Management Sciences

Vol. 4, No. 3, 601-618, 2019

https://dx.doi.org/10.33889/IJMEMS.2019.4.3-048

4.6 Geometry components of shallow footing made up of four foothills in Figure 6 including the form of inefficient perturbations $\Omega_{\widetilde{\sigma}_{i}}$ in finite element modeling.

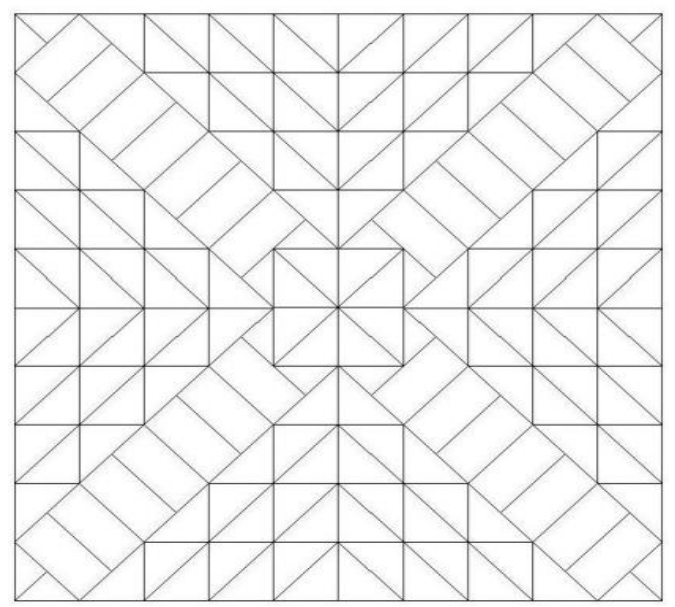

(a)

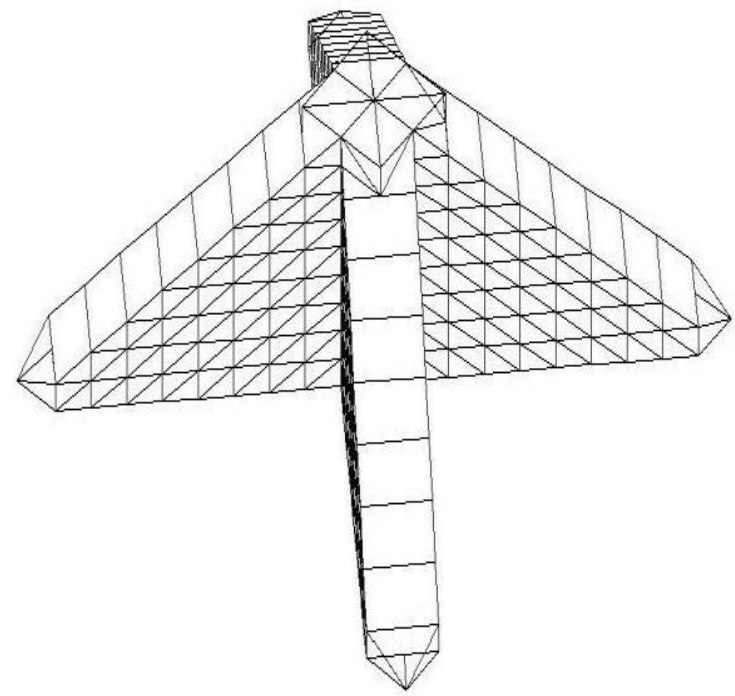

(c)

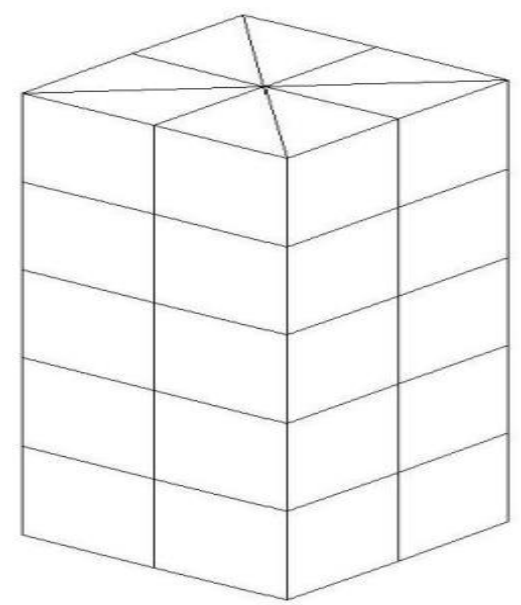

(b)

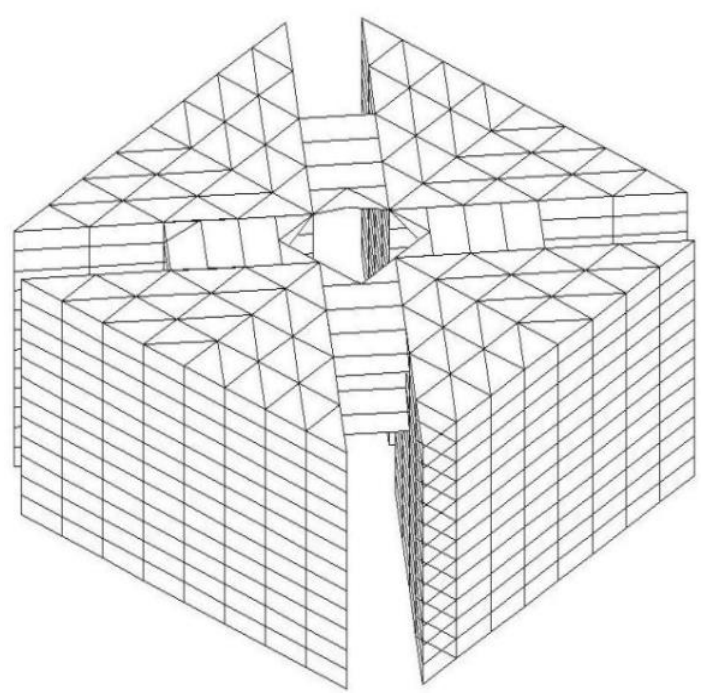

(d)

Figure 6.Top view of the final footing form for (a), column of the final footing form for (b), four foothills at the terminal iteration for (c) and form of inefficient perturbations $\Omega_{\widetilde{\sigma}_{\mathrm{i}}}$ for (d)

4.7 Variation of initial volume at a finite number of iterations and different rates in Figures 7 and 8. 
International Journal of Mathematical, Engineering and Management Sciences

Vol. 4, No. 3, 601-618, 2019

https://dx.doi.org/10.33889/IJMEMS.2019.4.3-048

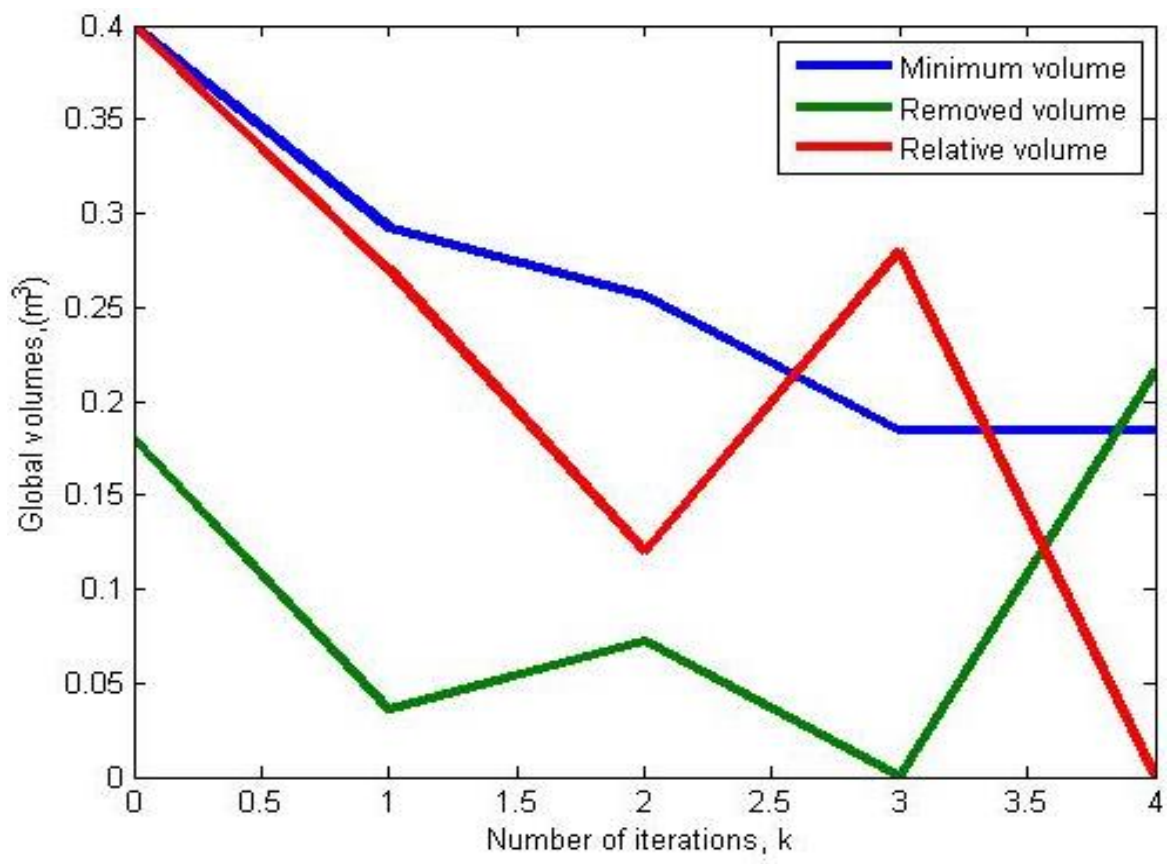

Figure 7 . Volume reduction stopped automatically at the terminal iteration $k=3$

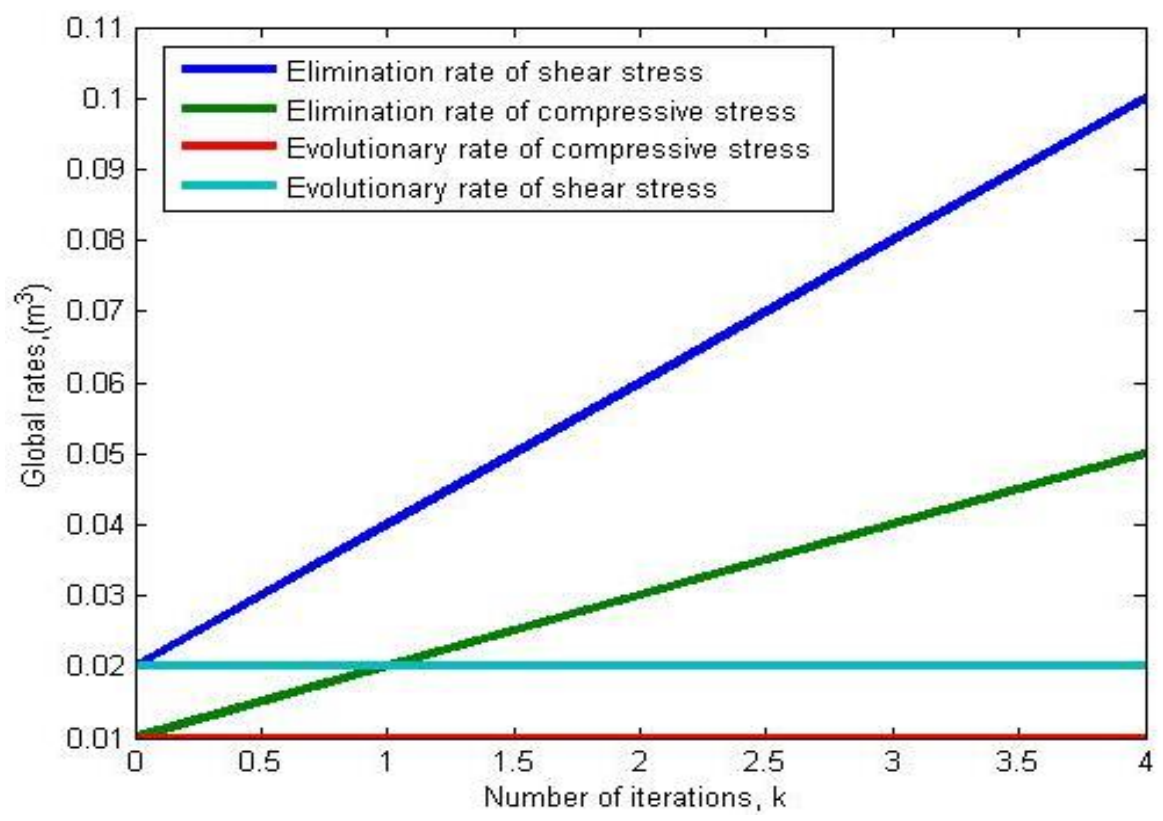

Figure 8. Elimination and evolutionary rates.

The elimination and evolutionary rates show that the shear stress is more active in the design of four foothills than the compressive stress due to the nature of concrete. 
International Journal of Mathematical, Engineering and Management Sciences

Vol. 4, No. 3, 601-618, 2019

https://dx.doi.org/10.33889/IJMEMS.2019.4.3-048

4.8 Representation of complex footing forms made up of more than four foothills of the same size in Figure 9.

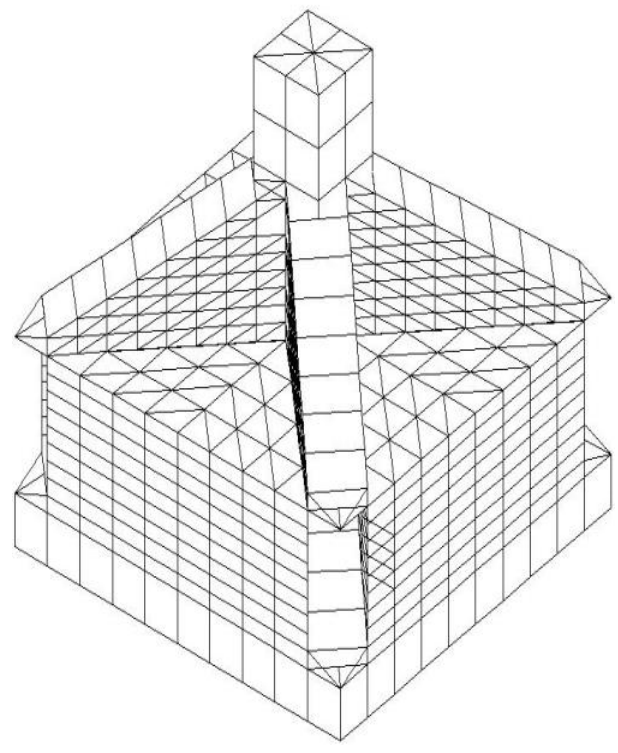

(a)

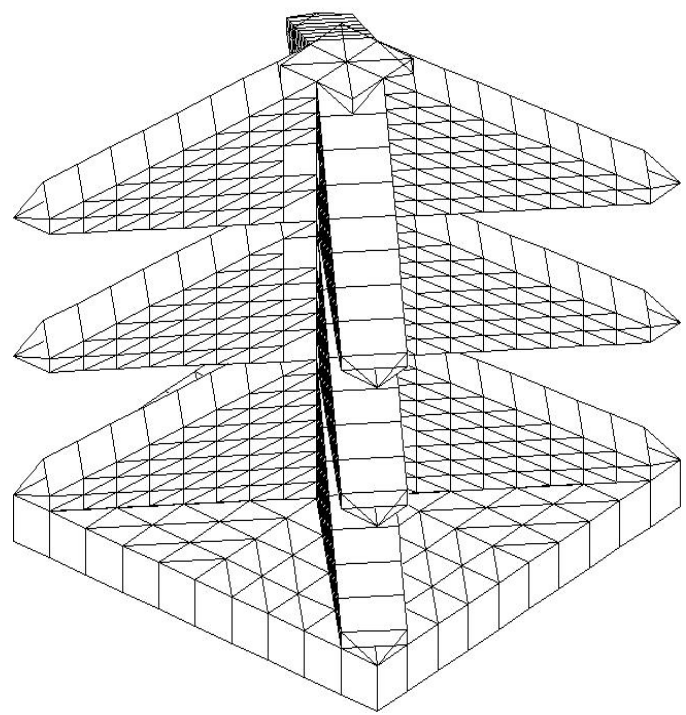

(c)

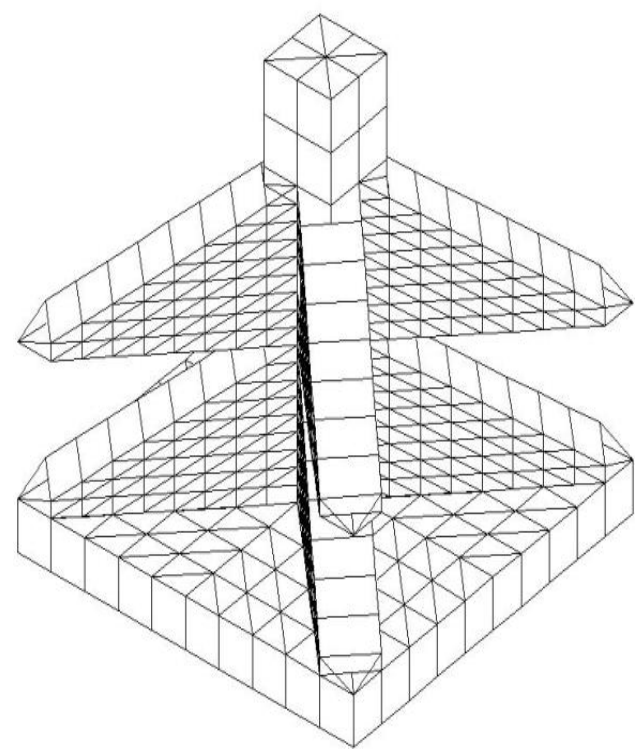

(b)

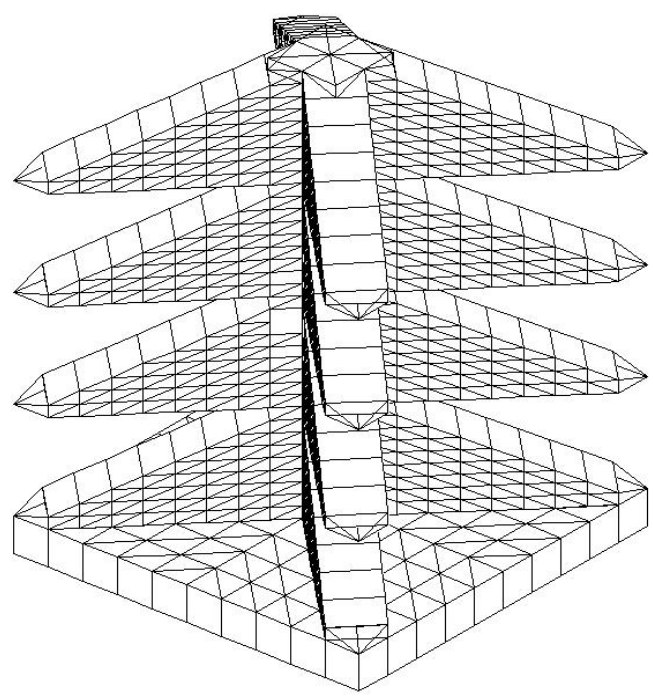

(d)

Figure 9. Complex footing forms based on finite element modeling for (a) with four foothills, for (b) with eight foothills, for (c) with twelve foothills and for (d) with sixteen foothills 
International Journal of Mathematical, Engineering and Management Sciences

Vol. 4, No. 3, 601-618, 2019

https://dx.doi.org/10.33889/IJMEMS.2019.4.3-048

\section{Conclusion}

In the absence of the exact footing form, a procedure has been developed to determine the optimal footing form made up of four foothills from the knowledge of the inexact footing forms. We have solved the inverse boundary value problem for linear elasticity and the stabilized solution has been used to formulate topology optimization problem with structural perturbations. By using the evolutionary structural optimization method, a serial of decisions has been made in order to minimize the initial volume, the structural perturbations in finite element modeling and the design constraints. We saw that the inefficient perturbations can be removed for every point of the inexact domain where the total loading force is not transferred while the fully stresses material of efficient perturbations is used to reinforce the design material. The results of the numerical experiment have provided the optimal footing form, the size of associated foothills and the form of geometric elements of inefficient perturbations. We have found that a finite number of foothills can be designed from inexact footing forms by modifying geometric elements of structural perturbations in finite elements modeling. This approach can be used to detect the dimensioning errors and also to avoid the rupture in shallow foundations. It brings more substantial changes in analysis of numerical instabilities of inexact forms and opens new perspectives on optimal control of points of geometry elements.

\section{Conflict of Interest}

The authors confirm that there is no conflict of interest to declare for this publication.

\section{Acknowledgements}

We thank the Department of Mathematics and Civil Engineering for their cooperation at the National Advanced School of Engineering (NASE/ UYI) in Yaounde, Cameroon. We would also like to show our gratitude to Ayissi Raoul Domingo, Professor of Mathematics at University of Yaoundé I for assistance on the manuscript at the department of mathematics. We thank the African Center of Excellence in Information and Communication technologies at the University of Yaounde I for their collaboration and support.

\section{References}

Ayissi, R.D., \& Etoua, R.M. (2017). Optimal control problem and viscosity solutions for the Vlasov equation in Yang-Mills charged Bianchi models. Advances in Pure and Applied Mathematics, 8(2), 129-140.

Bhunia, A.K., Duary, A., \& Sahoo, L. (2017). A genetic algorithm based hybrid approach for reliabilityredundancy optimization problem of a series system with multiple-choice. International Journal of Mathematical, Engineering and Management Sciences, 2(3), 185-212.

Bowles, J.E. (1996). Foundation analysis and design. 5th ed. New York: McGraw-Hill.

Das, B.M. (2010). Principles of foundation engineering. 7th edn. USA: Cengage Learning.

EN 1997(2004). Eurocode 7: Geotechnical design, part 1: general rules. European committee for Standardization, CEN, Brussels.

Engl, H.W., \& Groetsch, C.W. (Eds.). (2014). Inverse and ill-posed problems (Vol. 4). Elsevier. 
International Journal of Mathematical, Engineering and Management Sciences

Vol. 4, No. 3, 601-618, 2019

https://dx.doi.org/10.33889/IJMEMS.2019.4.3-048

Eskin, G., \& Ralston, J. (2002). On the inverse boundary value problem for linear isotropic elasticity. Inverse Problems, 18(3), 907-921.

Fellenius, B.H. (2018). Basics of foundation design. Pile Buck International, Inc.

Gajo, A., \& Smith, C.C. (2018). Combined rupture mechanisms in Shallow foundation. Canadian Geotechninical Journal, 55(6), 829-838.

Green, A.E., \& Zerna, W. (1968). Theoretical Elasticity, 2nd edition. Oxford University Press.

Hillyard, R.C., \& Braid, I.C. (1978). Analysis of dimensions and tolerances in computer-aided mechanical design. Computer-Aided Design, 10(3), 161-166.

Huang, X., \& Xie, Y.M. (2008). A new look at ESO and BESO optimization methods. Structural and Multidisciplinary Optimization, 35(1), 89-92.

Huang, X., \& Xie, Y.M. (2010). A further review of ESO type methods for topology optimization. Structural and Multidisciplinary Optimization, 41(5), 671-683.

Ikpe, A.E., Orhorhoro, E.K., \& Gobir, A. (2017). Design and reinforcement of a B-pillar for occupants safety in conventional vehicle applications. International Journal of Mathematical, Engineering and Management Sciences, 2(1), 37-52.

Jouve, F. (2014). Structural shape and topology optimization. In: Rozvany G.I.N., Lewiński T. (eds) Topology Optimization in Structural and Continuum Mechanics. CISM International Centre for Mechanical Sciences, (vol 549). Springer, Vienna.

Kumar, A., \& Ram, M. (2018). System reliability analysis based on Weibull distribution and hesitant fuzzy set. International Journal of Mathematical, Engineering and Management Sciences, 3(4), 513-521.

Larson, M.G., \& Bengzon, F. (2013). The finite element method: theory, implementation, and applications (Vol. 10). Springer Science \& Business Media.

Light, R. A., \& Gossard, D. C. (1983). Variational geometry: a new method for modifying part geometry for finite element analysis. Computers \& Structures, 17(5-6), 903-909.

Link, T.A. (1949). Interpretation of foothills structures, Alberta, Canada. AAPG Bulletin, 33(9), 1475-1501.

Mbock, K. (2009). A Novel algorithm for motion estimation with explicit considération of perturbations. Master Thesis, University of Heidelberg, Germany.

Mbock, K., Magloire, E.R., Minsili, L.S., \& Richard, O.M. (2019). Optimal mass design of 25 bar truss with loading conditions on five nodes elements. International Journal of Mathematical, Engineering and Management Sciences, 4(1), 1-16.

Miao, L., \& Bernitsas, M.M. (2006). Topology redesign for performance by large admissible perturbations. Structural and Mutidsciplinary Optimization, 31(2), 117-133.

Nakamura, G., \& Uhlmann, G. (2003). Global uniqueness for an inverse boundary value problem arising in elasticity. Inventiones Mathematicae, 152(1), 205-207.

Olchawa, A., \& Zawalski, A. (2014). Comparison of shallow foundation design using Eurocode 7 and Polish Standard. Journal of Water and Land Development, 20(1), 57-62.

Stetson, K.A., \& Palma, G.E. (1976). Inversion of first-order perturbation theory and its applications to structural design. AIAA Journal, 14(4), 454-460.

Suryatama, D., \& Bernitsas, M.M. (2000). Topology and performance redesign of complex structures by large admissible perturbations. Structural and Multidisciplinary Optimization, 20(2), 138-153.

Terzaghi, K., Peck, R.B., \& Mesri, G. (1996). Soil mechanics in engineering practice. Third Edition. John Wiley \& Sons, Inc. 
International Journal of Mathematical, Engineering and Management Sciences

Vol. 4, No. 3, 601-618, 2019

https://dx.doi.org/10.33889/IJMEMS.2019.4.3-048

Orr, T.L., \& Farrell, E.R. (2012). Geotechnical design to Eurocode 7. Springer Science \& Business Media.

Verpeaux, P., Charras, T., \& Millard, A. (1988). Castem 2000: une approche moderne du calcul des structures. Calcul des structures et intelligence artificielle, 2, 261-271.

Xie, Y.M, Feliceti, P., Tang, J.W. \& Burry, M.C. (2005). Form finding for complex structures using evolutionary structural optimization method. Design Studies, 26(1), 55-72.

Zong, Y., \& Mao, J. (2015). Tolerance mathematical modeling and analysis method based on control points of geometric element. Computer Aided Design and Applications, 12(6), 723-732.

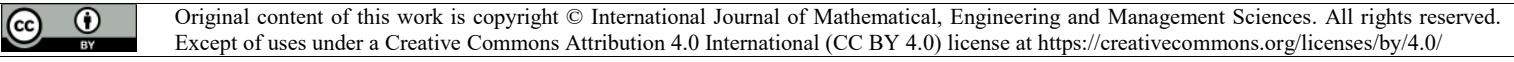

